\title{
MODELS OF MODERN CULTURAL RESEARCH
}

\section{Herchanivska P. E.}

\section{INTRODUCTION}

Each era is characterized by radical changes of the humanitarian paradigms. For the second half of the XX century these transformations are connected with the reorientation of the outlook on the globalization model of a society, based on the principle of multiculturalism. Changing of the vector of social development has determined the direction of the world social and humanitarian researches, focused on the concept of cultural diversity and intercultural communication. It should be noted that in Western liberal and communist doctrines, the model of multiculturalism acquires a different interpretation. In the liberal worldview, the idea of the primacy of man and his individual freedom dominates. Classical liberalism is characterized by the understanding of man as an autonomous and free subject, and culture is interpreted as one form of manifestation of his will. This formed the paradigmatic basis of European-American social and cultural anthropology of the second half of XX century.

However, the principles of liberalism did not fit into the ideological boundaries of communist doctrine, which relied on the idea of collective values. In essence, it is a conflict of ideologies belonging to axiologically diverse social and cultural environments. The ideological differences concerning the modeling of the cultural process in the space of globalization have become the moderator of the formation of the cultural-centrism orientation of the new science of culture. The liberal individualist view of human nature in cultural studies is opposed by the concept of man as the bearer of cultural values, as a subject whose ideals were crystallized in the conditions of the collective component's dominance over the individual in the public outlook.

Globalization processes have outlined a range of problems that went beyond the theoretical and methodological boundaries of some historically formed sciences about culture. The differentiation of the sciences, which has developed in modern humanities, was conditioned by their epistemological capabilities, which hindered the process of knowing the phenomenon of culture as a whole. At the same time, the gradual expansion of the demarcation boundaries of separate areas of knowledge caused to the crossing of their research fields. This determined the epistemological shift toward a non-classical model, the basis of which was the principle of integrative knowledge. Within 
cultural studies, there was an integration of the social sciences and humanities into a single system whose invariant basis was: 1) centering around the phenomenon of culture; 2) integration of knowledge areas about culture.

Cultural knowledge is contextual: cultural text is studied in the valuemeaning space of its era and rethought in the context of contemporary realities. Changing scientific paradigms of the era, the transformation of worldviews and values, norms of communication and social relations in the world community adjust the semantic field of cultural studies, without touching its invariant basis. The paradigm basis of cultural studies as a new configuration of knowledge is the principles of cultural-centrism, the integration of social and humanitarian knowledge, the contextualization of knowledge about culture, the recognition of multiple cultures and the need for intercultural dialogue.

One of the key tasks of the new field of knowledge is the development of an immanent methodological apparatus. Due to the heterogeneity of the subject field, the methodological complex of cultural studies encompasses a wide range of general and specific scientific methods and approaches that are most adapted to cultural paradigms. The work is devoted to perspective methodological directions, which were formed by transferring methodological principles of social and humanitarian disciplines into the problematic field of cultural studies.

\section{Culture analysis in the concept of systems theory}

The rise of scientific theories and hypotheses, which have made important changes to the conceptual scheme of cultural studies, have actualized the problem of developing fundamental methods for the study of social and cultural objects. One of the promising methodological directions of cultural studies is the systematic analysis, which was formed by transferring the basic principles of systems theory into the problematic field of cultural studies, combining the classical and non-classical research approaches of the natural sciences.

The purpose of the study is to develop a methodological model for the study of culture and society based on the principles of systems theory. It should be noted that system analysis has traditionally been associated with solving the problems of the natural sciences. However, with the accumulation of culturological knowledge, the identity of the processes occurring in culture and society, and the processes described by the theory of systems, becomes more and more obvious.

One of the first attempts to apply the systematic method in cultural studies belongs to L. White. In his works ${ }^{1,2,3}[12-14]$, he views culture as a coherent

${ }^{1}$ White L. (2002) The science of culture. Anthology of cultural studies. Interpretations of culture. St. Petersburg: St. Petersburg University, pp. 141-156. 
system consisting of material and spiritual elements. Developing the idea of the systemic nature of culture as an integral whole, B. Malinowski writes: "A cultural process that involves the material substrate of culture (artifacts), the social bonds witch bind people (standardized behaviors), and symbolic acts (the influence exerted by one organism on another through conditioned reflexes) is something holistic, that is, an independent system" $[8,687]$.

In cultural studies, system analysis is a set of methods and means of researching social and cultural objects as complex, multilevel and multicomponent systems. The analysis is based on a paradigm: any system consists of separate parts, interconnected by certain relationships; the system is in continuous development and interaction with the external environment.

Common to all methods of system analysis is: understanding the main purpose and functions of the system under study; the choice of the option of dividing the system into components (subsystems, elements), which is the most optimal for solving the set research goal; introduction of a hierarchy of parts in the structure of the system; function definition of each subsystem and the relationships between them; detecting the communication of the system to the external environment (or other systems); study the character of the system's variability, its ability to develop, adapt to the external environment.

System analysis in cultural studies is based on a set of universal and general scientific methods of research (structural analysis, comparative method, methods of formalization and modeling, etc.), each of which is determined by the purpose of the research and the specific task.

\section{Cultural systems and its classifications}

Many concepts necessary for understanding the functioning of social and cultural systems came in the cultural studies from thermodynamics. I. Prigozhin noted: "Appeal to the sciences witch study the complexity of the world does not mean that we propose to "reduce" the humanities to physics" $[9]$.

Let's define the key concept of the topic of our research "cultural system”. This is a combination of subsystems and elements of a cultural object, between which there is a natural connection and interaction, which determines its properties and regularities of functioning. The classification of systems depends from the criterion chosen, for example, from the nature of the

${ }^{2}$ White L. (2006) The concept of culture. Anthology of cultural studies. Interpretations of culture. 2nd ed. St. Petersburg: Petersburg University, pp. 17-48.

${ }^{3}$ White L. (2006) Energy and the evolution of culture. Anthology of cultural studies. Interpretations of culture. 2nd ed. St. Petersburg: St. Petersburg University, pp. 439-464.

${ }^{4}$ Malinovsky B. (2006) Functional Analysis. Anthology of cultural studies. Interpretations of culture. St. Petersburg: St. Petersburg University, pp. 681-702.

${ }^{5}$ Prigozhin I. (1991) Philosophy of instability. Problems of Philosophy. No 6, pp. 46-52. 
elements, their origin, the variability of properties, the degree of complexity, the attitude to the external environment, the reaction to the influences, the character of behavior and from the degree of participation of people in the implementation of managerial influences.

Depending on the nature of the elements, the systems are differentiated into real and abstract. Real (physical) systems are objects consisting of tangible elements. Abstract systems are composed of elements which have no direct analogues in the real world; it is a consequence of human thinking (ideas, theories, concepts, hypotheses, etc.). By origin, the systems are divided into natural and artificial. Natural systems are the product of the development of nature itself (climate, living organisms, the solar system). Social and cultural systems are artificial systems, the result of human creative activity.

By the degree of complexity, systems are distinguished into simple, complex and large. A simple system, as a rule, has a single-level structure, the relationship between elements of which is described by simple (linear) functions. A complex system contains a large number of interconnected subsystems, each of which can be broken down into separate elements. Such system is characterized by multidimensionality, hierarchical structure, diversity of nature of elements, connections, heterogeneity of structure. The choice of the criterion for the division of such a system into elements depends on the research goal. For example, based on the principle of social and cultural grouping, culture can be divided into such subsystems as world, local, national, ethnic, regional. The peculiarity of complex systems is that their integral properties differ from those of the individual constituent elements. Integration of complex systems leads to the formation of a macroscopic system.

Depending on the degree of variability of properties, systems can be divided into static and dynamic. When studying static systems, one can neglect the changes in their properties over time. Unlike static, dynamic systems change their state over time (discrete or continuous) under the influence of external and internal forces. Dynamic systems can be stable and unstable. A stable system is able to return to its original state after the cessation of forces, which brought it out of equilibrium. In an unstable dynamic system, on the contrary, even a slight change in the parameters of the structure or the nature of the connections between its elements leads to an unbalanced state of the system as a whole.

Dynamic systems are also divided into those that are regulated (by internal or external forces) and those that are self-organizing. The internal social and cultural regulation of the system is usually associated with the solution of such tasks as maintaining a certain level of social consolidation, providing collective forms of human life to meet individual and group interests and needs, eliminating the contradictions and stresses that arise in the process of human 
communication. The process of internal regulation of the system is carried out on the basis of pragmatic goals, taking into account the accumulated social experience of the community (enshrined in value orientations, customs, laws, rules, rules, ideology, beliefs, traditions, etc.). The forms and mechanisms of regulation reflect the specifics of the level of social and cultural development achieved by society. Relying on mass manipulation technologies (print and electronic media, advertising, etc.), institutional structures have an informational and psychological impact on the masses.

Let us turn to the question of differentiation of systems, the main criterion of which is the degree of connection of the system with the external environment. Based on this criterion, systems can be divided into isolated, closed and open. If an isolated system cannot exchange energy, substance or information with the external environment, and a closed system with its rigidly fixed boundaries is relatively independent of the surrounding social and cultural field, then the open system is oriented towards dialogue with the environment and intercultural interaction.

Processes in self-organizing systems develop quite differently. Such systems, according to H. Haken, "acquire their inherent structures or functions without any interference from the outside" ${ }^{6}[16,2]$, which leads to the formation of qualitatively new structures on a macroscopic scale. The study of these systems gave rise to a new scientific direction, called synergetics. It is an interdisciplinary field of scientific research whose task is to study natural phenomena and processes (including social and cultural ones) based on the principles of self-organization of complex systems. The founders of the synergy were the German physicist H. Haken and the Belgian physicist, Nobel Prize winner (1977) I. Prigozhin. According to H. Haken, "synergetics can be considered as part of a general system analysis, since both in synergetics and in system analysis, the common principles that underlie the functioning of the system are of major interest" ${ }^{7}[16,361]$.

\section{Synergistic model of culture development}

From the point of view of the synergetic model, culture and society are open, nonequilibrium, non-linear, self-organizing systems. Openness of the system is a necessary but insufficient condition for its self-organization: not any open system is self-organizing. This requires the presence of two opposite beginnings: the beginning that create the structure, and the beginning, that destroy it, leading to disorderly processes in the system, chaos (dissipation). The struggle of these principles (order and chaos) is the mechanism of

${ }^{6}$ Haken G. (1985) Synergetics: hierarchies of instabilities in self-organizing systems and devices. Moscow: World, p. 2.

${ }^{7}$ Ibid, p. 361. 
restructuring the old and the formation of a new social and cultural systems, which determines its self-development as a whole.

Consider the algorithm of the process of self-organization of the social and cultural systems, system. As A. Fleyer points out, the integrating core of any culture "is a relatively rigidly structured and hierarchical system of value orientations, forms and norms of social organization and regulation, languages and channels of social and cultural systems, communication, complexes of cultural institutions, of stratified lifestyles, ideology ceremonial and ritual forms of behavior, mechanisms of socialization and inculturation of personality, normative parameters of its social and cultural adequacy to the community, acceptable forms of innovative and creative action and so on" ${ }^{8}[15,392]$.

However, as the system develops, entropic phenomena appear. The growth of entropy processes leads to a crisis of identification of people, loss of value landmarks, traditional morality. The area of action of historically established and rooted in cultural traditions and institutional norms of socially acceptable patterns of consciousness and behavior of people is gradually reduced, illegal and criminal methods of solving social, economic and other problems are gaining popularity. At the same time, the area of influence of the marginal fields of culture is expanding, where forms of human activity are managed by marginal quasi-systems (such as thievery law, hip parties, rituals of esoteric sects, etc.).

The social and cultural system from the equilibrium state enters the nonequilibrium phase of its development, and the process of qualitative restructuring of its properties begins. Initially, the changes are slow, gradual. It is during this period that a new semantic integrity of culture is formed, and its new paradigm is crystallized. Thus, the state of chaos is a creative phase of the development of the social and cultural system, in the framework of which there is a reassessment of its semantic nucleus and the search for a new, more efficient configuration.

As a result of the accumulation of the internal forces of the system, entropy reaches a critical state, which leads to bifurcation (a jump-like qualitative restructuring of the system).Revolutionary processes are typical bifurcation processes, and the course of the post-revolutionary development of the system depends on many probability factors (internal, external), which often lead to the appearance of several alternative scenarios of its evolution.

An example of this is the multi-vector nature of the development paths of countries in the post-Soviet space. After bifurcation, relaxation occurs,

${ }^{8}$ Fleyer A. (1998) Sociocultural entropy. Culturology. XX century. Encyclopedia in 2 vol.: Vol. 2. St. Petersburg: University Book, pp. 392-393. 
that is, the gradual return of the system to a state of equilibrium, but in an updated form. This process is irreversible. It should be noted that the length of the relaxation period of the system, as well as the phases of its unbalanced state, significantly exceeds the bifurcation time period. So, through chaos and destruction of the structure, a new order is born in the system.

Intercultural interaction through the prism of system analysis

Systems theory reveals opportunities to address the issues directly related to the interaction of cultures as a factor in their development. The research algorithm has the following sequence: 1) a system analysis of each culture that comes into contact; 2) the study of the external environment, within which there is an interaction of social and cultural systems; 3) analysis of the interaction model of systems (equal - unequal, one-way - two-way); 4) determination of the mechanisms by which contact is made (the peaceful path or as a result of military and other conflicts); 5) the study of the dynamics of the interaction process and its consequences for each system.

A necessary and mandatory condition for intercultural interaction is the openness of the social and cultural system. Due to the variability of the parameters of the contacting systems in the chronotope, the dynamism and heterogeneity of the external environment, which are determined by objective factors, the result of the interaction of the systems often becomes probabilistic. The examples we consider demonstrate the great potential of systems theory and the wide possibilities of its application in the field of cultural studies both to solve theoretical problems (in particular, to study the regularities of social and cultural development of society), as well as to develop applied projects (development of state cultural policy strategy, modeling of intercultural interaction modern realities, etc.).

\section{Structural analysis: the culturology aspect}

The methodology of structural research is a set of structural method and its modifications (structural-functional, structural-typological, structuralpsychological methods), approaches, techniques and procedures related to the study of the architectonics of a particular social and cultural phenomenon and the internal relations of its components. The centering core of the methodology is structural analysis, which arose within the framework of structural linguistics. Its key concepts are sign, text and intertext.

As defined by Yu. Lotman, "the text appears before us not as an implementation of a message in any one language, but as a complex construction that preserves various codes and is able to transform received 
messages and generate new ones" ${ }^{9}[6,132]$. Within the framework of structural analysis, the concept of intertextuality comes to the fore.

The term intertextuality, introduced into the scientific circulation of Yu. Kristeva, means special dialogical relations of texts that are built as a mosaic of quotes: "Any text is a permutation of other texts, intertextuality; in the space of this or that text, several statements taken from other texts intersect and neutralize each other" ${ }^{10}[4,136]$. "Text in text" ${ }^{11}$ [7]. This is how Yu. Lotman describes this phenomenon. Developing the ideas of Kristeva, R. Barth wrote that any text "is entirely woven from quotes that refer to thousands of cultural sources. "...” All this is the language of culture, old and new, which pass through the text and create a powerful stereo sound"12 $[1,388 ; 418]$.

So, the intertext is the result of combining a certain text with a matrix of cultural texts (quotes), which belong to different value scales and different chronotopes, which determines the transformation of its content. From this point of view, text code becomes the key to understanding a certain type of culture, without which the intertext remains closed, incomprehensible.

One of the fundamental categories of structural analysis is the concept of border. The implementation of the structural methodology requires a clear demarcation of the research field, within which it is planned to determine the constituent elements of the object. The criterion of demarcation can be, for example, place, time, objects, phenomena.

Equally important is the question of the internal boundaries of intertext. In fact, the text is the result of penetration into the semiosphere of the author's text (recipient's text) the "alien” texts (donor's texts). We will call texts (or fragments of texts) from the works of other authors, which were introduced by the recipient into the intertext, as "strangers" texts. When dividing text into individual sectors, the boundaries of donor texts should be clearly defined.

Yu. Lotman names two motivating causes of interest in the "alien": "The first reason can be defined as "the search of himself", the second reason as "the search of alien" ${ }^{13}[6,111]$. In the general case, the author uses the donor text to confirm, clarify, specify his own thoughts, as a starting point (paradigm) in the development of a new concept. And it is not necessary that the donor text and the recipient text be synchronized over time and represent one cultural tradition. They can be in one chronotope (or different chronotopes), fit into one

${ }^{9}$ Lotman Yu. (1992) Featured Articles at 3 Vol.: Vol. 1: Articles on semiotics and cultural topology. Tallinn: Alexandra, p. 132.

${ }^{10}$ Kristeva Yu. (2004) Selected Works: The Destruction of Poetics. Moscow: ROSSPEN, p. 136.

${ }^{11}$ Lotman Yu. (1992) Culture and Explosion. Moscow: Gnosis, Progress.

${ }^{12}$ Barth R. (1989) Selected Works: Semiotics: Poetics. Moscow: Progress, p. 388, 418.

${ }^{13}$ Lotman Yu. (1992) Featured Articles at 3 Vol.: Vol.1: Articles on semiotics and cultural topology. Tallinn: Alexandra, p. 111. 
axiosphere (or different axiospheres). Texts in the field of intertext come into contact with each other, but, as M. Bachtin emphasizes, "this contact is a dialogical contact between texts, and not a mechanical contact of "opposition", which is possible only within the same text" ${ }^{14}[2,373]$.

Intertextual analysis provides not only knowledge about "alien" texts (which is a necessary condition for the perception of an author's text), but also opens up the possibility of reactualization of those meanings whose has been devalued over time and the output connotations was lost.

Yu. Lotman goes beyond linguistics, transferring the structural method to the entire cultural field ${ }^{15}[7,121]$. He describes a cultural phenomenon as an intertext. Expanding the capabilities of the structural method, he emphasizes: "The structural description is based on the allotment in the described object of system elements and connections that remain unchanged during any homomorphic transformations of the object"16 $[6,91]$.

Thus, the task of the researcher is to identify the structure of the object (text) by separating its elements, since it is the nature of the structure that determines the further algorithm of the study. Objects differentiate into simple and complex. A simple structure consists of elements, each of which is homogeneous. In this case, the research process is limited to the study of the properties of structural elements, features of their combination and relationships. Based on the results obtained, conclusions are drawn about the nature and specificity of the structure as a whole. In a complex structure, each element is heterogeneous and has an immanent architectonics, so the algorithm of the study becomes complicated and becomes multilevel.

R. Barth believed that the task of this analysis is "not to register some kind of stable structure, but rather to make movable textualization of the text (a structure that changes from reader to reader throughout history) in order to penetrate the semantic volume of the work in the process of its comprehension. “...” Our task is to think, imagine, experience the multiplicity of the text, the openness of the process of comprehension" ${ }^{17}[1,425]$. He disclosed an algorithm for this process: "To carry out textual analysis, we use some set of research procedures. “...” We will reduce these procedures to four points.

1. The text proposed for analysis is divided into segments (phrase, part of the phrase, the maximum group of three to four phrases), adjacent to each other and, as a rule, very short. “...” All these segments are units of reading,

\footnotetext{
${ }^{14}$ Bachtin M.M. (1979) Aesthetics of verbal creativity. Moscow: Art, p. 373.

${ }^{15}$ Lotman Yu. (1992) Culture and Explosion. Moscow: Gnosis, Progress, p. 121.

${ }^{16}$ Lotman Yu. (1992) Featured Articles at 3 Vol.: Vol.1: Articles on semiotics and cultural
} topology. Tallinn: Alexandra, p. 91.

${ }^{17}$ Barth R. (1989) Selected Works: Semiotics: Poetics. Moscow: Progress, p. 425. 
therefore I denote them by the term "lexia”. “...” Lexia is an arbitrary construct, it is just a segment within which we observe a distribution of meanings.

2.Then we are traced the meanings that arise within each lexia.

3. Our analysis will be built on the principle of gradual promotion: step by step we must go through the whole text. "...” This feature of our analysis is very important in the theoretical aspect: it means that we do not seek to reconstruct the structure of the text, but we seek to follow its structuralization and that the structuralization reading is more important to us than composition of the text.

4. It is important for us to show the starting points of the formation of sense, and not the final results (in fact, the meaning is nothing but a starting point). The basis of the text is not its internal closed structure, which is subject to exhaustive study, but access to other texts, other codes, other symbols; the text exists due to intertextual relations, due to intertextuality"18 [1, 426-428].

$\mathrm{R}$. Barth calls these phases as the operation of dismemberment and the operation of mounting. Barth replaced the classical analysis-synthesis by postmodern terms. He believed that these terms most accurately reflect the modern worldview and processes taking place in the art of the $\mathrm{XX}$ XXI centuries, beginning with the collages of P. Picasso and the decoupage of A. Matisse and ending with the subject abstractionism of contemporary artists (V. Voinov, L. Borisov, etc.). Reception dismemberment-mounting is becoming dominant in many types of contemporary art.

In fact, the binary opposition "dismemberment-mounting" is identical to “deconstruction-reconstruction" proposed by J. Derrida ${ }^{19}$ [3]. In the process of deconstruction-reconstruction, as well as during dismemberment-mounting, the unique is revealed that is implemented by the author in the text at an intuitive level. Thus, the main task of the analysis is the study of mid-text relationships, specifics and codes of elements of textual organization.

Structural methodology is widely used in cultural studies. It becomes multifunctional, supplemented by strategies of functional, typological, psychological and other methods. With its help, the structures of consciousness, psych, thinking, speech, as well as culture, history and modern society are studied.

\section{Structural and functional method}

The structural and functional methodology was formed on the foundation of functional and structural methods. If the task of the structural method in its classical version was limited to studying the architectonics of the

\footnotetext{
${ }^{18}$ Barth R. (1989) Selected Works: Semiotics: Poetics. Moscow: Progress, pp. 426-428.

${ }^{19}$ Derrida J. (2000) Something related to grammatology. Moscow: Ad Marginem.
} 
object and the character of the relationships of its structural elements, then the task of the structural-functional method is also the study of functional relationships both within the object of study and with the external environment.

The method is based on the paradigm of $\mathrm{B}$. Malinovsky on the inextricable connection of form and function of both social and cultural objects $^{20}[8,684]$. Let us dwell on the culturological aspect of the method and consider it through the culture-text-function matrix. Yu. Lotman notes: "If we take into account the following three categories, such as text, function and culture, then at least two general approaches are possible. In the first approach, culture is seen as a collection of texts. Then the function will fulfill the role of a certain metatext in relation to the texts. In the second approach, culture is considered as a set of functions" ${ }^{21}[6,133]$.

Interpreting culture from these positions, A. Radcliffe-Brown concludes that "culture is an integrated system. In the life of a particular community, each element of culture plays a special role, performs its specific function. “...” Only by understanding culture as a functioning system we can predict the results of any influence (intentional or not intentional) that affects it" ${ }^{22}$ [11, 634-635]. This conclusion is especially important when developing the problem of intercultural interaction in the context of intensified integration processes. By studying a specific culture as a functioning system, as well as the functional relationships between its elements, it is possible to predict with a certain degree of accuracy the consequences of exposure to another culture on it.

\section{Structural-typological method}

The structural-typological method of research solves other problems. If the structural-functional method is focused on the study of functional relationships between the structural elements of objects, the structuraltypological method is aimed at systematizing, classifying and grouping research objects according to the selected criterion. In contrast to the formal typological classification, this method allows not only to constitute the identity of the objects forming the groups, but also concretizes the results of typological studies based on the analysis of their structures. The algorithm of structuraltypological analysis of objects consists of the following phases: studying the structure of each research object by dividing it into separate components;

${ }^{20}$ Malinovsky B. (2006) Functional Analysis. Anthology of cultural studies. Interpretations of culture. St. Petersburg: St. Petersburg University, pp. 681-702 .

${ }^{21}$ Lotman Yu. (1992) Featured Articles at 3 Vol.: Vol.1: Articles on semiotics and cultural topology. Tallinn: Alexandra, p. 133.

${ }^{22}$ Radcliffe-Brown A. (2006) Historical and functional interpretations of culture and the practical application of anthropology in the management of indigenous peoples. Anthology of cultural studies. Interpretations of culture. 2nd ed. St. Petersburg: St. Petersburg University, pp. 633-635. 
definition (using comparative analysis) of cultural objects with the same structures and structural relationships; combining objects with identical structures into classes according to the selected criterion.

A few words from the history of this line of research. The structuraltypological method was introduced into scientific circulation by the Russian philologist-folklorist V. Propp in the work "Morphology of a fairy tale",23 [10]. Combining two methodological models (structural and typological), V. Propp significantly expands the possibilities of typological research, he focuses the attention of researchers on the correct choice of the criterion by which cultural classification is carried out. Using the typification of fairy tales as an example, he showed that the criterion, which is determined by the purpose and tasks of the study, must correspond to the optimal technological scheme, which leads to a rational organization of the research process.

The range of criteria for grouping cultural phenomena is very wide, for example, by morphological characteristics, by the place of cultural phenomena in the cultural and historical process (historical typology), by the level of community of people (regional, ethnic, national), by the level of stratification of society, by forms of worldview and social consciousness, by branches of social practice. Formed in a linguistic field, the structural-typological method becomes part of the methodological tools of cultural studies and gets the name "cultural classification method".

Within the framework of this method, objects of material and spiritual origin, social phenomena and systems, manifestations of the essential qualities of a person in the context of sociocultural development of societies can be grouped according to various typological characteristics.

\section{Structural-psychological method of J. Lacan}

The task of structural psychoanalysis by $\mathrm{J}_{\text {. Lacan }}{ }^{24}[5]$ is to determine and analyze the elements of the structure of the human psyche that determine the nature of the individual's behavior and culture. In his concept, J. Lacan relied on a paradigm: the unconscious is structured like a language; the functioning of each element of the unconscious is subject to the principle of systemicity.

The human psyche, according to J. Lacan, contains three interacting components: Imaginary, Symbolic and Real. Imaginary is a set of illusory representations that a person creates about himself. The imaginary obeys not the principle of reality, but the logic of illusion. It plays the role of the individual's mental self-defense in the process of communication. Symbolic is the sphere

${ }^{23}$ Propp V. (1998) Collection of works: in 4 vol. Vol. 2: Morphology of the "magic" fairy tale. The historical roots of a fairy tale. Moscow: Labyrinth.

${ }^{24}$ Lacan J. (1964) Four basic principles of psychoanalysis. Workshops: Part XI. Moscow: Gnosis, Logos. 
of social and cultural norms and ideas that the individual assimilates, as a rule, unconsciously, "symbolically", in the process of socialization. J. Lacan identifies the symbolic with language. Real, according to Lacan, is the sphere of biologically generated and mentally sublimated needs and impulses that are not given to the consciousness of the individual in any rationalized form accessible to him.

Such an approach determined Lacan's radical revision of the classical concept of "subject" and a rethinking of the essence of the connection between the subject and culture. If, according to the Cartesian tradition, the subject was considered as a carrier of consciousness and self-consciousness, then, according to Lacan, he appears as a function of culture. That is, according to Lacan, not culture is an attribute of an individual, but an individual is an attribute of culture.

In general, the structural psychoanalysis of J. Lacan led to a rethinking of the usual ideas about human psychology. Lacan's ideas regarding the correlation of the unconscious and language gave an impetus to a new interpretation of artistic creation, different from the modernist one.

\section{Specific methods of cultural research}

One of the promising methodological areas of modern cultural studies are cross-cultural researchers. The cross-cultural method arose within the framework of the American research tradition in the middle of the 20th century and became widespread in the social and humanitarian fields of knowledge in the comparative typological analysis of various cultures. It aims to identify universal and specific ways of behavior of individuals, social groups, organizations, institutions in the context of different cultures.

The purpose of the study is not so much in comparing cultures, but in comparing the different cultural practices in the context of various cultural traditions. Although the cross-cultural approach is more empirical, recently, there has been a tendency toward its transition to the level of philosophical generalizations and conclusions.

The research algorithm consists in choosing a criterion by which a comparative analysis of two (or more) cultures will be conducted; in identification and systematization of cultural phenomena of each culture, in according to the selected criterion; in understanding how these systems relate to each other; in establishment of factors determining the differences in the behavior of people in different cultures.

From the perspective of modern cultural paradigms (culture-centrism, the integration of social and humanitarian knowledge, the contextuality of knowledge about culture, recognition of the multiplicity of cultures and the need for intercultural dialogue), immanent cultural methods are formed. 
A social and cultural phenomenon begins to be interpreted as one of the forms of coding for a particular culture, and the dynamics of its development are comprehend as part of the process of communication of cultures with different codes (dialogue method). The dialogue method allows us to trace the reinterpretation of the phenomenon in the chronotope due to its recoding. Based on the communicative concept, the algorithm of information recoding during the transition from one art form to another is studied, for example, the transformation of the code of a literary text into a code of painting.

In the context of the development of the structural method, the reconstruction method of a cultural system based on an analysis of the binary nature of its invariant and variable components was developed. This method is aimed at solving genetic problems associated with the development of cultural forms.

Thus, in the process of the genesis of culturology, the methodological apparatus of social and humanitarian disciplines is adapted to its paradigms and the formation of inherent methods and approaches for solving urgent problems of our time.

\section{CONCLUSIONS}

The work reveals a paradigmatic foundation and an algorithm of research of promising methods of cultural studies which are focused on solving pressing social and humanitarian problems of our time.

1. In the framework of the theory of systems, social and cultural objects were classified according to a number of criteria (the nature of the elements, their origin, variability of properties, degree of complexity, attitude to the external environment, reaction of influence, models of human behavior, etc.). Particular attention was paid to the synergetic research model, with the help of which natural phenomena and processes (including social and cultural ones) are studied on the basis of the principles of self-organization of complex systems. From the perspective of systems theory, a synergistic model of cultural development was developed, as well as an algorithm for studying the problem of intercultural interaction.

2. The specificity of the structural method and its modifications (structural-functional, structural-typological, structural-psychological methodology) was considered. Appearing within of structural linguistics, this methodology has been transferred to the field of culture. It makes it possible to comprehend the meaning of social and cultural phenomena by differentiating an object into constituent elements, studying the properties of each of them, as well as the relationships between them. The modern structural methodology, supplemented by strategies of functional, typological, psychological methods, allows to study the functional relationships of the elements of the investigated 
objects, classify objects according to the selected criterion, and analyze the structure of the human psyche. Attention was also focused on immanent methods of culturological research (cross-cultural method, dialogue method, method of reconstructing the cultural system) that allow solving the problems of modern cultural studies.

\section{SUMMARY}

The section of the monograph is devoted to one of the fundamental problems of modern cultural studies, the methodological apparatus of this new field of knowledge. The basic research strategies developed within the framework of the leading areas of social and human sciences and adapted to solve current culturology problems are presented. Particular attention is paid to models of cultural studies developed on the basis of the theory of systems and the principles of structuralism. Their paradigm basis and research algorithm are revealed. The section presents the author's developments of their practical application, in particular, for the study of non-linear development of culture (synergetic model), intercultural interaction. The prospects of using the dialogue method based on the concept of communication and the author's method of reconstruction based on the principle of the binary nature of invariant and variable components of the cultural system are shown.

\section{REFERENCES}

1. Barth R. (1989) Selected Works: Semiotics: Poetics. Moscow: Progress (in Russian).

2. Bachtin M.M. (1979) Aesthetics of verbal creativity. Moscow: Art (in Russian).

3. Derrida J. (2000) Something related to grammatology. Moscow: Ad Marginem (in Russian).

4. Kristeva Yu. (2004) Selected Works: The Destruction of Poetics. Moscow: ROSSPEN (in Russian).

5. Lacan J. (1964) Four basic principles of psychoanalysis. Workshops: Part XI. Moscow: Gnosis, Logos (in Russian).

6. Lotman Yu. (1992) Featured Articles at 3 Vol.: Vol.1: Articles on semiotics and cultural topology. Tallinn: Alexandra (in Estonia).

7. Lotman Yu. (1992) Culture and Explosion. Moscow: Gnosis, Progress (in Russian).

8. Malinovsky B. (2006) Functional Analysis. Anthology of cultural studies. Interpretations of culture. St. Petersburg: St. Petersburg University, pp. 681-702 (in Russian).

9. Prigozhin I. (1991) Philosophy of instability. Problems of Philosophy. No 6, pp. 46-52 (in Russian). 
10. Propp V. (1998) Collection of works: in 4 vol. Vol. 2: Morphology of the "magic" fairy tale. The historical roots of a fairy tale. Moscow: Labyrinth (in Russian).

11. Radcliffe-Brown A. (2006) Historical and functional interpretations of culture and the practical application of anthropology in the management of indigenous peoples. Anthology of cultural studies. Interpretations of culture. 2nd ed. St. Petersburg: St. Petersburg University, pp. 633-635 (in Russian).

12. White L. (2002) The science of culture. Anthology of cultural studies. Interpretations of culture. St. Petersburg: St. Petersburg University, pp.141-156 (in Russian).

13. White L. (2006) The concept of culture. Anthology of cultural studies. Interpretations of culture. 2nd ed. St. Petersburg: Petersburg University, pp. 17-48.

14. White L. (2006) Energy and the evolution of culture. Anthology of cultural studies. Interpretations of culture. 2nd ed. St. Petersburg: St. Petersburg University, pp. 439-464 (in Russian).

15. Fleyer A. (1998) Sociocultural entropy. Culturology. XX century. Encyclopedia in 2 vol.: Vol.2. St. Petersburg: University Book, pp. 392-393. (in Russian).

16. Haken G. (1985) Synergetics: hierarchies of instabilities in selforganizing systems and devices. Moscow: World (in Russian).

\section{Information about the author:} Herchanivska P. E., orcid.org/0000-0003-3647-6265

Doctor of Cultural Studies, Professor, Head of the Department of Cultural Studies and information communications, The National Academy of Culture and Arts Management 9, Lavrska str. Bldg. 15, 01015, Kyiv, Ukraine 